\title{
Some Common Fixed Point Theorems for Four Mappings in Dislocated Metric Space
}

\author{
Dinesh Panthi' ${ }^{1}$ Kumar Subedi² \\ ${ }^{1}$ Department of Mathematics, Valmeeki Campus, Nepal Sanskrit University, Kathmandu, Nepal \\ ${ }^{2}$ Department of Mathematics Education, Mahendra Ratna Multiple Campus, Tribhuvan University, Ilam, Nepal \\ Email:panthid06@gmail.com
}

How to cite this paper: Panthi, D. and Subedi, K. (2016) Some Common Fixed Point Theorems for Four Mappings in Dislocated Metric Space. Advances in Pure Mathematics, 6, 695-712.

http://dx.doi.org/10.4236/apm.2016.610057

Received: August 9, 2016

Accepted: September 19, 2016

Published: September 22, 2016

Copyright $(9) 2016$ by authors and Scientific Research Publishing Inc. This work is licensed under the Creative Commons Attribution International License (CC BY 4.0).

http://creativecommons.org/licenses/by/4.0/

\begin{abstract}
In this article, we establish some common fixed point theorems for two pairs of weakly compatible mappings with (E. A.) and (CLR) property in dislocated metric space which generalize and extend some similar results in the literature.
\end{abstract}

\section{Keywords}

Dislocated Metric, Weakly Compatible Maps, Common Fixed Point

\section{Introduction}

In 1986, S. G. Matthews [1] introduced some concepts of metric domains in the context of domain theory. In 2000, P. Hitzler and A. K. Seda [2] introduced the concept of dislocated topology where the initiation of dislocated metric space is appeared. Since then, many authors have established fixed point theorems in dislocated metric space. In the literature, one can find many interesting recent articles in the field of dislocated metric space (see examples [3]-[12]). Dislocated metric space plays very important role in topology, semantics of logical programming and in electronics engineering.

The purpose of this article is to establish some common fixed point theorems for two pairs of weakly compatible mappings with (E. A.) and (CLR) property in dislocated metric space.

\section{Preliminaries}

We start with the following definitions, lemmas and theorems.

Definition 1. [2] Let $X$ be a non empty set and let $d: X \times X \rightarrow[0, \infty)$ be a function satisfying the following conditions:

1) $d(x, y)=d(y, x)$. 
2) $d(x, y)=d(y, x)=0$ implies $x=y$.

3) $d(x, y) \leq d(x, z)+d(z, y)$ for all $x, y, z \in X$.

Then, $d$ is called dislocated metric (or $d$-metric) on $X$ and the pair $(X, d)$ is called the dislocated metric space (or d-metric space).

Definition 2. [2] A sequence $\left\{x_{n}\right\}$ in a d-metric space $(X, d)$ is called a Cauchy sequence if for given $\epsilon>0$, there corresponds $n_{0} \in N$ such that for all $m, n \geq n_{0}$, we have $d\left(x_{m}, x_{n}\right)<\epsilon$.

Definition 3. [2] A sequence in d-metric space converges with respect to $d$ (or in d) if there exists $x \in X$ such that $d\left(x_{n}, x\right) \rightarrow 0$ as $n \rightarrow \infty$.

Definition 4. [2] $A$ d-metric space $(X, d)$ is called complete if every Cauchy sequence in it is convergent with respect to $d$.

Lemma 1. [2] Limits in a d-metric space are unique.

Definition 5. Let $A$ and $S$ be two self mappings on a set $X$. If $A x=S x$ for some $x \in X$, then $x$ is called coincidence point of $A$ and $S$.

Definition 6. [13] Let $A$ and $S$ be mappings from a metric space $(X, d)$ into itself. Then, $A$ and $S$ are said to be weakly compatible if they commute at their coincident point, that is, $A x=S x$ for some $x \in X$ implies $A S x=S A x$.

Definition 7. [14] Let $A$ and $S$ be two self mappings defined on a metric space $(X, d)$. We say that the mappings $A$ and $S$ satisfy $(E . A$.) property if there exists a sequence $\left\{x_{n}\right\} \in X$ such that

$$
\lim _{n \rightarrow \infty} A x_{n}=\lim _{n \rightarrow \infty} S x_{n}=u
$$

for some $x \in X$.

Definition 8. [15] Let $A$ and $S$ be two self mappings defined on a metric space $(X, d)$. We say that the mappings $A$ and $S$ satisfy $\left(C L R_{A}\right)$ property if there exists a sequence $\left\{x_{n}\right\} \in X$ such that

$$
\lim _{n \rightarrow \infty} A x_{n}=\lim _{n \rightarrow \infty} S x_{n}=A x
$$

\section{Main Results}

Now, we establish a common fixed point theorem for two pairs of weakly compatible mappings using E. A. property.

Theorem 1. Let $(X, d)$ be a dislocated metric space. Let $A, B, S, T: X \rightarrow X$ satisfying the following conditions

$$
\begin{aligned}
& \qquad A(X) \subseteq S(X) \text { and } B(X) \subseteq T(X) \\
& \qquad d(A x, B y) \leq k\{d(S y, A x)+d(T x, S y)+d(T x, A x)+d(B y, S y)+d(T x, B y)\} \\
& k \in\left[0, \frac{1}{8}\right) \\
& \text { 1) The pairs }(A, T) \text { or }(B, S) \text { satisfy E. A. property. } \\
& \text { 2) The pairs }(A, T) \text { and }(B, S) \text { are weakly compatible. } \\
& \text { If } T(X) \text { is closed then }
\end{aligned}
$$

1) The maps $A$ and Thave a coincidence point. 
2) The maps $B$ and $S$ have a coincidence point.

3) The maps $A, B, S$ and $T$ have an unique common fixed point.

Proof. Assume that the pair $(A, T)$ satisfy E. A. property, so there exists a sequence $\left\{x_{n}\right\} \in X$ such that

$$
\lim _{n \rightarrow \infty} A x_{n}=\lim _{n \rightarrow \infty} T x_{n}=u
$$

for some $u \in X$. Since $A(X) \subseteq S(X)$, so there exists a sequence $\left\{y_{n}\right\} \in X$ such that $A x_{n}=S y_{n}$. Hence,

$$
\lim _{n \rightarrow \infty} A x_{n}=\lim _{n \rightarrow \infty} S y_{n}=u
$$

From condition (2), we have

$$
d\left(A x_{n}, B y_{n}\right) \leq k\left\{d\left(S y_{n}, A x_{n}\right)+d\left(T x_{n}, S y_{n}\right)+d\left(T x_{n}, A x_{n}\right)+d\left(B y_{n}, S y_{n}\right)+d\left(T x_{n}, B y_{n}\right)\right\}
$$

Taking limit as $n \rightarrow \infty$, we get

$$
\begin{gathered}
\lim _{n \rightarrow \infty} d\left(A x_{n}, B y_{n}\right) \leq \\
\lim _{n \rightarrow \infty} k\left\{d\left(S y_{n}, A x_{n}\right)+d\left(T x_{n}, S y_{n}\right)+d\left(T x_{n}, A x_{n}\right)\right. \\
\left.+d\left(B y_{n}, S y_{n}\right)+d\left(T x_{n}, B y_{n}\right)\right\}
\end{gathered}
$$

Since

$$
\begin{gathered}
\lim _{n \rightarrow \infty} d\left(T x_{n}, S y_{n}\right)=\lim _{n \rightarrow \infty} d\left(T x_{n}, A x_{n}\right)=\lim _{n \rightarrow \infty} d\left(S y_{n}, A x_{n}\right)=0 \\
\lim _{n \rightarrow \infty} d\left(B y_{n}, S y_{n}\right)=\lim _{n \rightarrow \infty} d\left(T x_{n}, B y_{n}\right)=d\left(B y_{n}, u\right)
\end{gathered}
$$

Therefore we have,

$$
\lim _{n \rightarrow \infty} d\left(u, B y_{n}\right) \leq 2 k \lim _{n \rightarrow \infty} d\left(u, B y_{n}\right)
$$

which is a contradiction, since $k \in\left[0, \frac{1}{8}\right)$. Hence, $\lim _{n \rightarrow \infty} B y_{n}=u$. Now, we have

$$
\lim _{n \rightarrow \infty} A x_{n}=\lim _{n \rightarrow \infty} T x_{n}=\lim _{n \rightarrow \infty} B y_{n}=\lim _{n \rightarrow \infty} S y_{n}=u
$$

Assume $T(X)$ is closed, then there exits $v \in X$ such that $T v=u$. We claim that $A v=u$. Now, from condition (2)

$$
d\left(A v, B y_{n}\right) \leq k\left\{d\left(S y_{n}, A v\right)+d\left(T v, S y_{n}\right)+d(T v, A v)+d\left(B y_{n}, S y_{n}\right)+d\left(T v, B y_{n}\right)\right\}
$$

Since

$$
\begin{gathered}
\lim _{n \rightarrow \infty} d\left(S y_{n}, A v\right)=d(u, A v) \\
\lim _{n \rightarrow \infty} d\left(T v, S y_{n}\right)=\lim _{n \rightarrow \infty} d\left(B y_{n}, S y_{n}\right)=\lim _{n \rightarrow \infty} d\left(T v, B y_{n}\right)=0
\end{gathered}
$$

So, taking limit as $n \rightarrow \infty$ in (5), We conclude that

$$
d(A v, u) \leq 2 k d(u, A v)
$$

which is a contradiction. Hence, $d(A v, u)=0 \Rightarrow A v=u$. Now, we have

$$
A v=u=T v \text {. }
$$

This proves that $v$ is the coincidence point of $(A, T)$.

Again, since $A(X) \subseteq S(X)$ so there exists $w \in X$ such that 


$$
A v=S w=u
$$

Now, we claim that $B w=u$. From condition (2)

$$
\begin{aligned}
d(u, B w) & =d(A v, B w) \\
& \leq k\{d(S w, A v)+d(T v, S w)+d(T v, A v), d(B w, S w)+d(T v, B w)\} \\
& =k\{d(u, u)+d(u, u)+d(u, u)+d(B w, u)+d(u, B w)\} \\
& =k\{3 d(u, u)+2 d(B w, u)\} \\
& \leq 8 k d(u, B w)
\end{aligned}
$$

which is a contradiction.

Hence, $d(u, B w)=0 \Rightarrow B w=u$.

Therefore, $B w=u=S w$.

This represents that $w$ is the coincidence point of the maps $B$ and $S$.

Hence,

$$
u=B w=S w=T v=A v
$$

Since the pairs $(B, S)$ and $(A, T)$ are weakly compatible so,

$$
\begin{gathered}
B S w=S B w, \quad T A v=A T v \\
T u=T A v=A T v=A u \text { and } S u=S B w=B S w=B u
\end{gathered}
$$

We claim $B u=u$. From condition (2)

$$
\begin{aligned}
d(u, B u) & =d(A v, B u) \\
& \leq k\{d(S u, A v)+d(T v, S u)+d(T v, A v)+d(B u, S u)+d(T v, B u)\} \\
& =k\{d(B u, u)+d(u, B u)+d(u, u)+d(B u, B u)+d(u, B u)\} \\
& =k\{3 d(u, B u)+d(u, u)+d(B u, B u)\} \\
& \leq 7 k d(u, B u)
\end{aligned}
$$

which is a contradiction.

Hence, $d(u, B u)=0 \Rightarrow B u=u$.

Therefore, $u=B u=S u$. Similary, $A u=u=T u$. Hence, $u=A u=B u=S u=T u$. This represents that $u$ is the common fixed point of the mappings $A, B, S$ and $T$.

\section{Uniqueness:}

If possible, let $z(\neq u)$ be other common fixed point of the mappings, then by the condition (2)

$$
\begin{aligned}
d(u, z) & =d(A u, B z) \\
& \leq k\{d(S z, A u)+d(T u, S z)+d(T u, A u)+d(B z, S z)+d(T u, B z)\} \\
& =k\{d(z, u)+d(u, z)+d(u, u)+d(z, z)+d(u, z)\} \\
& =k\{3 d(u, z)+d(u, u)+d(z, z)\} \\
& \leq 7 k d(u, z)
\end{aligned}
$$

which is a contradiction.

Hence, $d(u, z)=0 \Rightarrow u=z$. This establishes the uniqueness of the common fixed point of four mappings. 
From the above theorem, one can obtain the following corollaries easily.

Corollary 1. Let $(X, d)$ be a dislocated metric space. Let $A, S, T: X \rightarrow X$ satisfying the following conditions

$$
\begin{gathered}
A(X) \subseteq S(X) \text { and } A(X) \subseteq T(X) \\
d(A x, A y) \leq k\{d(S y, A x)+d(T x, S y)+d(T x, A x)+d(A y, S y)+d(T x, A y)\} \\
k \in\left[0, \frac{1}{8}\right) .
\end{gathered}
$$

1) The pairs $(A, T)$ or $(A, S)$ satisfy E. A. property.

2) The pairs $(A, T)$ and $(A, S)$ are weakly compatible.

If $T(X)$ is closed then,

1) The maps $A$ and Thave a coincidence point.

2) The maps $A$ and $S$ have a coincidence point.

3) The maps $A, S$ and $T$ have an unique common fixed point.

Corollary 2. Let $(X, d)$ be a dislocated metric space. Let $A, B, S: X \rightarrow X$ satisfying the following conditions

$$
\begin{aligned}
& \qquad A(X) \text { and } B(X) \subseteq S(X) \\
& \qquad d(A x, B y) \leq k\{d(S y, A x)+d(S x, S y)+d(S x, A x)+d(B y, S y)+d(S x, B y)\} \\
& k \in\left[0, \frac{1}{8}\right) . \\
& \text { 1) The pairs }(A, S) \text { or }(B, S) \text { satisfy E. A. property. } \\
& \text { 2) The pairs }(A, S) \text { and }(B, S) \text { are weakly compatible. } \\
& \text { If T(X) is closed then, } \\
& \text { 1) The maps } A \text { and } S \text { have a coincidence point. } \\
& \text { 2) The maps } B \text { and } S \text { have a coincidence point. } \\
& \text { 3) The maps } A, B \text { and } S \text { have an unique common fixed point. }
\end{aligned}
$$

Corollary 3. Let $(X, d)$ be a dislocated metric space. Let $A, S: X \rightarrow X$ satisfying the following conditions

$$
\begin{gathered}
A(X) \subseteq S(X) \\
d(A x, A y) \leq k\{d(S y, A x)+d(S x, S y)+d(S x, A x)+d(A y, S y)+d(S x, A y)\} \\
k \in\left[0, \frac{1}{8}\right) .
\end{gathered}
$$

1) The pair (A,S) satisfy $E$. A. property.

2) The pair $(A, S)$ is weakly compatible.

If $S(X)$ is closed, then the mappings $A$ and $S$ have an unique common fixed point.

Now, we establish the following theorem.

Theorem 2. Let $(X, d)$ be a dislocated metric space. Let $A, B, S, T: X \rightarrow X$ satisfying the following conditions

$$
A(X) \subseteq S(X) \text { and } B(X) \subseteq T(X)
$$




$$
\begin{aligned}
& d(A x, B y) \leq k \max \{d(S y, A x), d(T x, S y), d(T x, A x), d(B y, S y), d(T x, B y)\} \\
& k \in\left[0, \frac{1}{2}\right) .
\end{aligned}
$$

1) The pairs $(A, T)$ or $(B, S)$ satisfy E. A. property.

2) The pairs $(A, T)$ and $(B, S)$ are weakly compatible.

If $T(X)$ is closed then,

1) The maps $A$ and Thave a coincidence point.

2) The maps $B$ and $S$ have a coincidence point.

3) The maps $A, B, S$ and $T$ have an unique common fixed point.

Proof. Assume that the pair $(A, T)$ satisfy E. A. property, so there exists a sequence $\left\{x_{n}\right\} \in X$ such that

$$
\lim _{n \rightarrow \infty} A x_{n}=\lim _{n \rightarrow \infty} T x_{n}=u
$$

for some $u \in X$. Since $A(X) \subseteq S(X)$, so there exists a sequence $\left\{y_{n}\right\} \in X$ such that $A x_{n}=S y_{n}$. Hence,

$$
\lim _{n \rightarrow \infty} A x_{n}=\lim _{n \rightarrow \infty} S y_{n}=u
$$

From condition (9), we have

$d\left(A x_{n}, B y_{n}\right) \leq k \max \left\{d\left(S y_{n}, A x_{n}\right), d\left(T x_{n}, S y_{n}\right), d\left(T x_{n}, A x_{n}\right), d\left(B y_{n}, S y_{n}\right), d\left(T x_{n}, B y_{n}\right)\right\}$

Taking limit as $n \rightarrow \infty$ we get

$\lim _{n \rightarrow \infty} d\left(A x_{n}, B y_{n}\right) \leq \lim _{n \rightarrow \infty} k \max \left\{d\left(S y_{n}, A x_{n}\right), d\left(T x_{n}, S y_{n}\right), d\left(T x_{n}, A x_{n}\right), d\left(B y_{n}, S y_{n}\right), d\left(T x_{n}, B y_{n}\right)\right\}$

Since

$$
\begin{gathered}
\lim _{n \rightarrow \infty} d\left(T x_{n}, S y_{n}\right)=\lim _{n \rightarrow \infty} d\left(T x_{n}, A x_{n}\right)=\lim _{n \rightarrow \infty} d\left(S y_{n}, A x_{n}\right)=0 \\
\lim _{n \rightarrow \infty} d\left(B y_{n}, S y_{n}\right)=\lim _{n \rightarrow \infty} d\left(T x_{n}, B y_{n}\right)=d\left(B y_{n}, u\right)
\end{gathered}
$$

Therefore we have,

$$
\lim _{n \rightarrow \infty} d\left(u, B y_{n}\right) \leq k \lim _{n \rightarrow \infty} d\left(u, B y_{n}\right)
$$

which is a contradiction, since $k \in\left[0, \frac{1}{2}\right)$. Hence, $\lim _{n \rightarrow \infty} B y_{n}=u$. Now, we have

$$
\lim _{n \rightarrow \infty} A x_{n}=\lim _{n \rightarrow \infty} T x_{n}=\lim _{n \rightarrow \infty} B y_{n}=\lim _{n \rightarrow \infty} S y_{n}=u
$$

Assume $T(X)$ is closed, then there exits $v \in X$ such that $T v=u$. We claim that $A v=u$. Now from condition (9)

$$
d\left(A v, B y_{n}\right) \leq k \max \left\{d\left(S y_{n}, A v\right), d\left(T v, S y_{n}\right), d(T v, A v), d\left(B y_{n}, S y_{n}\right), d\left(T v, B y_{n}\right)\right\}
$$

Since

$$
\begin{gathered}
\lim _{n \rightarrow \infty} d\left(S y_{n}, A v\right)=d(u, A v) \\
\lim _{n \rightarrow \infty} d\left(T v, S y_{n}\right)=\lim _{n \rightarrow \infty} d\left(B y_{n}, S y_{n}\right)=\lim _{n \rightarrow \infty} d\left(T v, B y_{n}\right)=0
\end{gathered}
$$

So, taking limit as $n \rightarrow \infty$ in (12), We conclude that 


$$
d(A v, u) \leq k d(u, A v)
$$

which is a contradiction. Hence, $d(A v, u)=0 \Rightarrow A v=u$. Now, we have

$$
A v=u=T v \text {. }
$$

This proves that $v$ is the coincidence point of $(A, T)$.

Again, since $A(X) \subseteq S(X)$ so there exists $w \in X$ such that

$$
A v=S w=u
$$

Now we claim that $B w=u$. From condition (9)

$$
\begin{aligned}
d(u, B w) & =d(A v, B w) \\
& \leq k \max \{d(S w, A v), d(T v, S w), d(T v, A v), d(B w, S w), d(T v, B w)\} \\
& =k \max \{d(u, u), d(u, u), d(u, u), d(B w, u), d(u, B w)\} \\
& =k \max \{d(u, u), d(B w, u)\}
\end{aligned}
$$

Since

$$
d(u, u) \leq 2 d(u, B w)
$$

So if $\max \{d(u, u), d(B w, u)\}=d(u, u)$ or $d(B w, u)$ we get the contradiction, since

$$
d(u, B w) \leq 2 k d(u, B w)
$$

or

$$
d(u, B w) \leq k d(u, B w)
$$

Hence, $d(u, B w)=0 \Rightarrow B w=u$.

Therefore, $B w=u=S w$.

This represents that $w$ is the coincidence point of the maps $B$ and $S$.

Hence,

$$
u=B w=S w=T v=A v
$$

Since the pairs $(B, S)$ and $(A, T)$ are weakly compatible so,

$$
\begin{gathered}
B S w=S B w, \quad T A v=A T v \\
T u=T A v=A T v=A u \text { and } S u=S B w=B S w=B u
\end{gathered}
$$

We claim $B u=u$. From condition (9)

$$
\begin{aligned}
& d(u, B u)=d(A v, B u) \\
& \leq k \max \{d(S u, A v), d(T v, S u), d(T v, A v), d(B u, S u), d(T v, B u)\} \\
& =k \max \{d(B u, u), d(u, B u), d(u, u), d(B u, B u), d(u, B u)\} \\
& =k \max \{d(u, B u), d(u, u), d(B u, B u)\}
\end{aligned}
$$

Since

$$
d(u, u) \leq 2 d(u, B u) \text { and } d(B u, B u) \leq 2 d(u, B u)
$$

So if $\max \{d(u, B u), d(u, u), d(B u, B u)\}=d(u, B u)$ or $d(u, u)$ or $d(B u, B u)$ we get the contradiction. Since,

$$
d(u, B u)=d(A v, B u) \leq k d(u, B u)
$$


or

$$
d(u, B u) \leq 2 k d(u, B u)
$$

Hence, $d(u, B u)=0 \Rightarrow B u=u$.

Therefore, $u=B u=S u$. Similary, $A u=u=T u$. Hence, $u=A u=B u=S u=T u$. This represents that $u$ is the common fixed point of the mappings $A, B, S$ and $T$.

\section{Uniqueness:}

If possible, let $z(\neq u)$ be other common fixed point of the mappings, then by the condition (9)

$$
\begin{aligned}
d(u, z) & =d(A u, B z) \\
& \leq k \max \{d(S z, A u) d(T u, S z), d(T u, A u), d(B z, S z), d(T u, B z)\} \\
& =k \max \{d(z, u), d(u, z), d(u, u), d(z, z), d(u, z)\} \\
& =k \max \{d(u, z), d(u, u), d(z, z)\}
\end{aligned}
$$

Since

$$
d(u, u) \leq 2 d(u, z) \text { and } d(z, z) \leq 2 d(z, u)
$$

So if $\max \{d(u, z), d(u, u), d(z, z)\}=d(u, z)$ or $d(u, u)$ or $d(z, z)$ we get the contradiction, since

$$
d(u, z)=d(A u, B z) \leq k d(u, z)
$$

or

$$
d(u, z) \leq 2 k d(u, z)
$$

Hence, $d(u, z)=0 \Rightarrow u=z$. This establishes the uniqueness of the common fixed point of four mappings.

From the above theorem, we can establish the following corollaries:

Corollary 4. Let $(X, d)$ be a dislocated metric space. Let $A, S, T: X \rightarrow X$ satisfying the following conditions

$$
A(X) \subseteq S(X) \text { and } A(X) \subseteq T(X)
$$

$$
d(A x, A y) \leq k \max \{d(S y, A x), d(T x, S y), d(T x, A x), d(A y, S y), d(T x, A y)\}
$$

$k \in\left[0, \frac{1}{2}\right)$.

1) The pairs $(A, T)$ or $(A, S)$ satisfy $E$. A. property.

2) The pairs $(A, T)$ and $(A, S)$ are weakly compatible.

If $T(X)$ is closed then

1) The maps $A$ and $T$ have a coincidence point.

2) The maps $A$ and $S$ have a coincidence point.

3) The maps $A, S$ and $T$ have an unique common fixed point.

Corollary 5. Let $(X, d)$ be a dislocated metric space. Let $A, B, S: X \rightarrow X$ satisfying the following conditions

$$
A(X) \text { and } B(X) \subseteq S(X)
$$




$$
\begin{aligned}
& d(A x, B y) \leq k \max \{d(S y, A x), d(S x, S y), d(S x, A x), d(B y, S y), d(S x, B y)\} \\
& k \in\left[0, \frac{1}{2}\right) .
\end{aligned}
$$

1) The pairs $(A, S)$ or $(B, S)$ satisfy E. A. property.

2) The pairs $(A, S)$ and $(B, S)$ are weakly compatible.

if $T(X)$ is closed then

1) The maps $A$ and $S$ have a coincidence point.

2) The maps $B$ and $S$ have a coincidence point.

3) The maps $A, B$ and $S$ have an unique common fixed point.

Corollary 6. Let $(X, d)$ be a dislocated metric space. Let $A, S: X \rightarrow X$ satisfying the following conditions

$$
\begin{aligned}
& \qquad A(X) \subseteq S(X) \\
& \qquad(A x, A y) \leq k \max \{d(S y, A x), d(S x, S y), d(S x, A x), d(A y, S y), d(S x, A y)\} \\
& k \in\left[0, \frac{1}{2}\right) . \\
& \text { 1) The pair }(A, S) \text { satisfy E. A. property. } \\
& \text { 2) The pair }(A, S) \text { is weakly compatible. } \\
& \text { If } S(X) \text { is closed, then the mappings } A \text { and } S \text { have an unique common fixed point. }
\end{aligned}
$$

Now, we establish a common fixed point theorem for weakly compatible mappings using (CLR)-property.

Theorem 3. Let $(X, d)$ be a dislocated metric space. Let $A, B, S, T: X \rightarrow X$ satisfying the following conditions

$$
\begin{aligned}
& A(X) \subseteq S(X) \text { and } B(X) \subseteq T(X) \\
& d(A x, B y) \leq k M(x, y), \quad k \in\left[0, \frac{1}{8}\right)
\end{aligned}
$$

where,

$$
M(x, y)=\{d(T x, S y)+d(T x, A x)+d(B y, S y)+d(T x, B y)+d(S y, A x)\}
$$

1) The pairs $(A, T)$ or $(B, S)$ satisfy CLR-property.

2) The pairs $(A, T)$ and $(B, S)$ are weakly compatible.

Then

1) The maps $A$ and Thave a coincidence point.

2) The maps $B$ and $S$ have a coincidence point.

3) The maps $A, B, S$ and $T$ have an unique common fixed point.

Proof. Assume that the pair $(A, T)$ satisfy $\left(C L R_{A}\right)$ property, so there exists a sequence $\left\{x_{n}\right\} \in X$ such that

$$
\lim _{n \rightarrow \infty} A x_{n}=\lim _{n \rightarrow \infty} T x_{n}=A x
$$

for some $x \in X$. Since $A(X) \subseteq S(X)$, so there exists a sequence $\left\{y_{n}\right\} \in X$ such that $\lim _{n \rightarrow \infty} A x_{n}=\lim _{n \rightarrow \infty} S y_{n}=A x$. We show that

$$
\lim _{n \rightarrow \infty} B x_{n}=A x
$$


From condition (16), we have

$$
d\left(A x_{n}, B y_{n}\right) \leq k M\left(x_{n}, y_{n}\right),
$$

where

$$
M\left(x_{n}, y_{n}\right)=\left\{d\left(T x_{n}, S y_{n}\right)+d\left(T x_{n}, A x_{n}\right)+d\left(B y_{n}, S y_{n}\right)+d\left(T x_{n}, B y_{n}\right)+d\left(S y_{n}, A x_{n}\right)\right\}
$$

Taking limit as $n \rightarrow \infty$ in (20), we get

$$
\lim _{n \rightarrow \infty} d\left(A x_{n}, B y_{n}\right) \leq k \lim _{n \rightarrow \infty} M\left(x_{n}, y_{n}\right),
$$

Since

$$
\begin{gathered}
\lim _{n \rightarrow \infty} d\left(T x_{n}, S y_{n}\right)=\lim _{n \rightarrow \infty} d\left(T x_{n}, A x_{n}\right)=\lim _{n \rightarrow \infty} d\left(S y_{n}, A x_{n}\right)=0 \\
\lim _{n \rightarrow \infty} d\left(A x_{n}, B y_{n}\right)=\lim _{n \rightarrow \infty} d\left(A x, B y_{n}\right)=\lim _{n \rightarrow \infty} d\left(B y_{n}, S y_{n}\right)
\end{gathered}
$$

Hence, we have

$$
\lim _{n \rightarrow \infty} d\left(A x, B y_{n}\right) \leq 2 k \lim _{n \rightarrow \infty} d\left(A x, B y_{n}\right) \text {, }
$$

which is a contradiction, since $k \in\left[0, \frac{1}{8}\right)$.

Therefore,

$$
\lim _{n \rightarrow \infty} d\left(A x, B y_{n}\right)=0 \Rightarrow \lim _{n \rightarrow \infty} B y_{n}=A x .
$$

Now we have

$$
\lim _{n \rightarrow \infty} A x_{n}=\lim _{n \rightarrow \infty} T x_{n}=\lim _{n \rightarrow \infty} B y_{n}=\lim _{n \rightarrow \infty} S y_{n}=A x
$$

Assume $A(X) \subseteq S(X)$, then there exits $v \in X$ such that $A x=S v$.

We claim that $B v=S v$.

Now from condition (16)

$$
d\left(A x_{n}, B v\right) \leq k M\left(x_{n}, v\right)
$$

where

$$
M\left(x_{n}, v\right)=\left\{d\left(T x_{n}, S v\right)+d\left(T x_{n}, A x_{n}\right)+d(B v, S v)+d\left(T x_{n}, B v\right)+d\left(S v, A x_{n}\right)\right\}
$$

Since

$$
\begin{gathered}
\lim _{n \rightarrow \infty} d\left(T x_{n}, B v\right)=d(A x, B v)=d(S v, B v) \\
\lim _{n \rightarrow \infty} d\left(T x_{n}, S v\right)=\lim _{n \rightarrow \infty} d\left(T x_{n}, A x_{n}\right)=\lim _{n \rightarrow \infty} d\left(S v, A x_{n}\right)=0
\end{gathered}
$$

So, taking limit as $n \rightarrow \infty$ in (22), we conclude that

$$
d(S v, B v) \leq 2 k d(S v, B v)
$$

which is a contradiction.

Hence, $d(S v, B v)=0 \Rightarrow S v=B v$.

This proves that $v$ is the coincidence point of the maps $B$ and $S$.

Therefore, $S v=B v=A x=w($ Say $)$.

Since the pair $(B, S)$ is weakly compatible, so 


$$
B S v=S B v \Rightarrow B w=S w
$$

Since $B(X) \subseteq T(X)$, there exists a point $u \in X$ such that $B v=T u$. We show that

$$
T u=A u=w
$$

From condition (16),

$$
d(A u, B v) \leq k M(u, v)
$$

where,

$$
\begin{aligned}
M(u, v) & =\{d(T u, S v)+d(T u, A u)+d(B v, S v)+d(T u, B v)+d(S v, A u)\} \\
& =\{d(B v, B v)+d(B v, A u)+d(B v, B v)+d(B v, B v)+d(B v, A u)\} \\
& =\{3 d(B v, B v)+2 d(B v, A u)\} \\
& \leq 8 d(B v, A u)
\end{aligned}
$$

Therefore, $d(A u, B v)=0 \Rightarrow A u=B v$.

$$
\therefore A u=B v=T u=w
$$

This proves that $u$ is the coincidence point of the maps $A$ and $T$.

Since the pair $(A, T)$ is weakly compatible so,

$$
A T u=T A u \Rightarrow A w=T w
$$

We show that $A w=w$.

From condition (16)

$$
d(A w, w)=d(A w, B v) \leq k M(w, v)
$$

where

$$
\begin{aligned}
M(w, v) & =\{d(T w, S v)+d(T w, A w)+d(B v, S v)+d(T w, B v)+d(S v, A w)\} \\
& =\{d(A w, w)+d(A w, A w)+d(w, w)+d(A w, w)+d(w, A w)\} \\
& =\{3 d(A w, w)+d(A w, A w)+d(w, w)\} \\
& \leq 7 k d(A w, w)
\end{aligned}
$$

which is a contradiction.

Hence, $d(A w, w)=0 \Rightarrow A w=w$. Similarly, we obtain $B w=w$.

$\therefore A w=B w=S w=T w=w$. Hence, $w$ is the common fixed point of four mappings $A, B, S$ and $T$.

\section{Uniqueness:}

Let $z(\neq w)$ be other common fixed point of the mappings $A, B, S$ and $T$, then by the condition (16)

$$
d(w, z)=d(A w, B z) \leq k M(w, z)
$$

where

$$
\begin{aligned}
M(w, z) & =\{d(T w, S z)+d(T w, A w)+d(B z, S z)+d(T w, B z)+d(S z, A w)\} \\
& =\{d(w, z)+d(w, w)+d(z, z)+d(w, z)+d(z, w)\} \\
& =\{3 d(w, z)+d(w, w)+d(z, z)\} \\
& \leq 7 d(w, z)
\end{aligned}
$$

which is a contradiction. 
Hence, $d(w, z)=0 \Rightarrow w=z$. This establishes the uniqueness of the common fixed point.

Now we have the following corollaries:

Corollary 7. Let $(X, d)$ be a dislocated metric space. Let $A, B, S: X \rightarrow X$ satisfying the following conditions

$$
\begin{gathered}
A(X), B(X) \subseteq S(X) \\
d(A x, B y) \leq k M(x, y), \quad k \in\left[0, \frac{1}{8}\right)
\end{gathered}
$$

where

$$
M(x, y)=\{d(S x, S y)+d(S x, A x)+d(B y, S y)+d(S x, B y)+d(S y, A x)\}
$$

1) The pairs $(A, S)$ or $(B, S)$ satisfy CLR-property.

2) The pairs $(A, S)$ and $(B, S)$ are weakly compatible.

Then

1) The maps $A$ and $S$ have a coincidence point.

2) The maps $B$ and $S$ have a coincidence point.

3) The maps $A, B$ and $S$ have an unique common fixed point.

Corollary 8. Let $(X, d)$ be a dislocated metric space. Let $A, S, T: X \rightarrow X$ satisfying the following conditions

$$
\begin{aligned}
& A(X) \subseteq S(X) \text { and } A(X) \subseteq T(X) \\
& d(A x, A y) \leq k M(x, y), \quad k \in\left[0, \frac{1}{8}\right)
\end{aligned}
$$

where

$$
M(x, y)=\{d(T x, S y)+d(T x, A x)+d(A y, S y)+d(T x, A y)+d(S y, A x)\}
$$

1) The pair $(A, T)$ and $(A, S)$ satisfy CLR-property.

2) The pairs $(A, T)$ and $(A, S)$ are weakly compatible.

Then

1) The maps $A$ and Thave a coincidence point.

2) The maps $A$ and $S$ have a coincidence point.

3) The maps $A, S$ and $T$ have an unique common fixed point.

Corollary 9. Let $(X, d)$ be a dislocated metric space. Let $A, S: X \rightarrow X$ satisfying the following conditions

$$
\begin{gathered}
A(X) \subseteq S(X) \\
d(A x, A y) \leq k M(x, y), \quad k \in\left[0, \frac{1}{8}\right)
\end{gathered}
$$

where

$$
M(x, y)=\{d(S x, S y)+d(S x, A x)+d(A y, S y)+d(S x, A y)+d(S y, A x)\}
$$

1) The pair $(A, S)$ satisfy CLR-property.

2) The pair $(A, S)$ is weakly compatible. 


\section{Then}

1) The maps $A$ and $S$ have a coincidence point.

2) The maps $A$ and $S$ have an unique common fixed point.

Now, we establish the following theorem.

Theorem 4. Let $(X, d)$ be a dislocated metric space. Let $A, B, S, T: X \rightarrow X$ satisfying the following conditions

$$
\begin{aligned}
& A(X) \subseteq S(X) \text { and } B(X) \subseteq T(X) \\
& d(A x, B y) \leq k M(x, y), \quad k \in\left[0, \frac{1}{2}\right)
\end{aligned}
$$

where

$$
M(x, y)=\max \{d(T x, S y), d(T x, A x), d(B y, S y), d(T x, B y), d(S y, A x)\}
$$

1) The pairs $(A, T)$ or $(B, S)$ satisfy $C L R$-property.

2) The pairs $(A, T)$ and $(B, S)$ are weakly compatible.

then

1) The maps $A$ and Thave a coincidence point.

2) The maps $B$ and $S$ have a coincidence point.

3) The maps $A, B, S$ and $T$ have an unique common fixed point.

Proof. Assume that the pair $(A, T)$ satisfy $\left(C L R_{A}\right)$ property, so there exists a sequence $\left\{x_{n}\right\} \in X$ such that

$$
\lim _{n \rightarrow \infty} A x_{n}=\lim _{n \rightarrow \infty} T x_{n}=A x
$$

for some $x \in X$. Since $A(X) \subseteq S(X)$, so there exists a sequence $\left\{y_{n}\right\} \in X$ such that $\lim _{n \rightarrow \infty} A x_{n}=\lim _{n \rightarrow \infty} S y_{n}=A x$. We show that

$$
\lim _{n \rightarrow \infty} B x_{n}=A x
$$

From condition (26), we have

$$
d\left(A x_{n}, B y_{n}\right) \leq k M\left(x_{n}, y_{n}\right),
$$

where

$$
M\left(x_{n}, y_{n}\right)=\max \left\{d\left(T x_{n}, S y_{n}\right), d\left(T x_{n}, A x_{n}\right), d\left(B y_{n}, S y_{n}\right), d\left(T x_{n}, B y_{n}\right), d\left(S y_{n}, A x_{n}\right)\right\}
$$

Taking limit as $n \rightarrow \infty$ in (30), we get

$$
\lim _{n \rightarrow \infty} d\left(A x_{n}, B y_{n}\right) \leq k \lim _{n \rightarrow \infty} M\left(x_{n}, y_{n}\right) \text {, }
$$

Since

$$
\begin{gathered}
\lim _{n \rightarrow \infty} d\left(T x_{n}, S y_{n}\right)=\lim _{n \rightarrow \infty} d\left(T x_{n}, A x_{n}\right)=\lim _{n \rightarrow \infty} d\left(S y_{n}, A x_{n}\right)=0 \\
\lim _{n \rightarrow \infty} d\left(T x_{n}, B y_{n}\right)=\lim _{n \rightarrow \infty} d\left(B y_{n}, S y_{n}\right)=\lim _{n \rightarrow \infty} d\left(A x, B y_{n}\right)
\end{gathered}
$$

Hence, we have

$$
\lim _{n \rightarrow \infty} d\left(A x, B y_{n}\right) \leq k \lim _{n \rightarrow \infty} d\left(A x, B y_{n}\right)
$$


which is a contradiction, since $k \in\left[0, \frac{1}{2}\right)$.

Hence,

$$
\lim _{n \rightarrow \infty} d\left(A x, B y_{n}\right)=0 \Rightarrow \lim _{n \rightarrow \infty} B y_{n}=A x
$$

Now, we have

$$
\lim _{n \rightarrow \infty} A x_{n}=\lim _{n \rightarrow \infty} T x_{n}=\lim _{n \rightarrow \infty} B y_{n}=\lim _{n \rightarrow \infty} S y_{n}=A x
$$

Assume $A(X) \subseteq S(X)$, then there exits $v \in X$ such that $A x=S v$.

We claim that $B v=S v$.

Now from condition (26)

$$
d\left(A x_{n}, B v\right) \leq k M\left(x_{n}, v\right)
$$

where

$$
M\left(x_{n}, v\right)=\max \left\{d\left(T x_{n}, S v\right), d\left(T x_{n}, A x_{n}\right), d(B v, S v), d\left(T x_{n}, B v\right), d\left(S v, A x_{n}\right)\right\}
$$

Since

$$
\begin{gathered}
\lim _{n \rightarrow \infty} d\left(T x_{n}, B v\right)=d(A x, B v)=d(S v, B v) \\
\lim _{n \rightarrow \infty} d\left(T x_{n}, S v\right)=\lim _{n \rightarrow \infty} d\left(T x_{n}, A x_{n}\right)=\lim _{n \rightarrow \infty} d\left(S v, A x_{n}\right)=0
\end{gathered}
$$

So, taking limit as $n \rightarrow \infty$ in (32) We conclude that

$$
d(S v, B v) \leq k d(S v, B v) \text {, }
$$

which is a contradiction. Hence, $d(S v, B v)=0 \Rightarrow S v=B v$. This proves that $v$ is the coincidence point of of the maps $B$ and $S$.

Hence, $S v=B v=A x=w($ Say $)$.

Since the pair $(B, S)$ is weakly compatible, so

$$
B S v=S B v \Rightarrow B w=S w
$$

Since $B(X) \subseteq T(X)$ there exists a point $u \in X$ such that $B v=T u$. We show that

$$
T u=A u=w
$$

From condition (26)

$$
d(A u, B v) \leq k M(u, v),
$$

where

$$
\begin{aligned}
M(u, v) & =\max \{d(T u, S v), d(T u, A u), d(B v, S v), d(T u, B v), d(S v, A u)\} \\
& =\max \{d(B v, B v), d(B v, A u), d(B v, B v), d(B v, B v), d(B v, A u)\} \\
& =\max \{d(B v, B v), d(B v, A u)\}
\end{aligned}
$$

Hence

$$
d(A u, B v) \leq k \max \{d(B v, B v), d(B v, A u)\}
$$

Since

$$
d(B v, B v) \leq 2 d(A u, B v)
$$


So if $\max \{d(B v, B v), d(B v, A u)\}=d(B v, B v)$ or $d(B v, A u)$, we get the contradiction for both cases.

Therefore, $d(A u, B v)=0 \Rightarrow A u=B v$.

$$
\therefore A u=B v=T u=w
$$

This proves that $u$ is the coincidence point of the maps $A$ and $T$.

Since the pair $(A, T)$ is weakly compatible so,

$$
A T u=T A u \Rightarrow A w=T w
$$

We show that $A w=w$.

From condition (26)

$$
d(A w, w)=d(A w, B v) \leq k M(w, v),
$$

where

$$
\begin{aligned}
M(w, v) & =\max \{d(T w, S v), d(T w, A w), d(B v, S v), d(T w, B v), d(S v, A w)\} \\
& =\max \{d(A w, w), d(A w, A w), d(w, w), d(A w, w), d(w, A w)\} \\
& =\max \{d(A w, w), d(A w, A w), d(w, w)\}
\end{aligned}
$$

Since

$$
d(A w, A w) \leq 2 d(A w, w) \text { and } d(w, w) \leq 2 d(A w, w)
$$

So if $\max \{d(A w, w), d(A w, A w), d(w, w)\}=d(A w, w)$ or $d(A w, A w)$ or $d(w, w)$ we have

$$
d(A w, w) \leq k d(A w, w) \quad \text { or } \quad \leq 2 k d(A w, w)
$$

which give contradictions for all three cases.

Hence, $d(A w, w)=0 \Rightarrow A w=w$. Similarly, we obtain $B w=w$.

$\therefore A w=B w=S w=T w=w$. Hence, $w$ is the common fixed point of four mappings $A, B, S$ and $T$.

Uniqueness:

Let $z(\neq w)$ be other common fixed point of the mappings $A, B, S$ and $T$, then by the condition (26)

$$
d(w, z)=d(A w, B z) \leq k M(w, z)
$$

where

$$
\begin{aligned}
M(w, z) & =\max \{d(T w, S z), d(T w, A w), d(B z, S z), d(T w, B z), d(S z, A w)\} \\
& =\max \{d(w, z), d(w, w), d(z, z), d(w, z), d(z, w)\} \\
& =\max \{d(w, z), d(w, w), d(z, z)\}
\end{aligned}
$$

Since

$$
d(w, w) \leq 2 d(w, z) \text { and } d(z, z) \leq 2 d(z, w)
$$

So if $\max \{d(w, z), d(w, w), d(z, z)\}=d(w, z)$ or $d(w, w)$ or $d(z, z)$ we have

$$
d(w, z)=d(A w, B z) \leq k M(w, z) \leq k d(w, z)
$$

or

$$
d(w, z) \leq 2 k d(w, z)
$$


which give contradictions for all three cases.

Hence, $d(w, z)=0 \Rightarrow w=z$. This establishes the uniqueness of the common fixed point.

Now, we have the following corollaries:

Corollary 10. Let $(X, d)$ be a dislocated metric space. Let $A, B, S: X \rightarrow X$ satisfying the following conditions

$$
\begin{gathered}
A(X), B(X) \subseteq S(X) \\
d(A x, B y) \leq k M(x, y), \quad k \in\left[0, \frac{1}{2}\right)
\end{gathered}
$$

where

$$
M(x, y)=\max \{d(S x, S y), d(S x, A x), d(B y, S y), d(S x, B y), d(S y, A x)\}
$$

1) The pairs $(A, S)$ or $(B, S)$ satisfy CLR-property.

2) The pairs $(A, S)$ and $(B, S)$ are weakly compatible.

Then

1) The maps $A$ and $S$ have a coincidence point.

2) The maps $B$ and $S$ have a coincidence point.

3) The maps $A, B$ and $S$ have an unique common fixed point.

Corollary 11. Let $(X, d)$ be a dislocated metric space. Let $A, S, T: X \rightarrow X$ satisfying the following conditions

$$
\begin{aligned}
& A(X) \subseteq S(X) \text { and } A(X) \subseteq T(X) \\
& d(A x, A y) \leq k M(x, y), \quad k \in\left[0, \frac{1}{2}\right)
\end{aligned}
$$

where

$$
M(x, y)=\max \{d(T x, S y), d(T x, A x), d(A y, S y), d(T x, A y), d(S y, A x)\}
$$

1) The pair $(A, T)$ and $(A, S)$ satisfy CLR-property.

2) The pairs $(A, T)$ and $(A, S)$ are weakly compatible.

Then

1) The maps $A$ and Thave a coincidence point.

2) The maps $A$ and $S$ have a coincidence point.

3) The maps $A, S$ and $T$ have an unique common fixed point.

Corollary 12. Let $(X, d)$ be a dislocated metric space. Let $A, S: X \rightarrow X$ satisfying the following conditions

$$
\begin{gathered}
A(X) \subseteq S(X) \\
d(A x, A y) \leq k M(x, y), \quad k \in\left[0, \frac{1}{2}\right)
\end{gathered}
$$

where

$$
M(x, y)=\max \{d(S x, S y), d(S x, A x), d(A y, S y), d(S x, A y), d(S y, A x)\}
$$

1) The pair $(A, S)$ satisfy CLR-property. 
2) The pair $(A, S)$ is weakly compatible.

Then

1) The maps $A$ and $S$ have a coincidence point.

2) The maps $A$ and $S$ have an unique common fixed point.

Remarks: Our results generalize and extend the results of A. Amri and D. Moutawakil [14], W. Sintunavarat and P. Kumam [15] in dislocated metric space.

\section{References}

[1] Matthews, S.G. (1986) Metric Domains for Completeness. Technical Report 76, Ph.D. Thesis, Department of Computer Science, University of Warwick, Coventry.

[2] Hitzler, P. and Seda, A.K. (2000) Dislocated Topologies. Journal of Electrical Engineering, 51, 3-7.

[3] Kumari, P.S., Zoto, K. and Panthi, D. (2015) d-Neighborhood System and Generalized FContraction in Dislocated Metric Space. SpringerPlus, 4, 1-10. http://dx.doi.org/10.1186/s40064-015-1095-3

[4] Kumari, P.S. (2012) Common Fixed Point Theorems on Weakly Compatible Maps on Dislocated Metric Spaces. Mathematical Sciences, 6, 71. http://dx.doi.org/10.1186/2251-7456-6-71

[5] Kumari, P.S. and Panthi, D. (2015) Cyclic Contractions and Fixed Point Theorems on Various Generating Spaces. Fixed Point Theory and Applications, 2016, 28. http://dx.doi.org/10.1186/s13663-016-0521-8

[6] Kumari, P.S., Ramana, C.V., Zoto, K. and Panthi, D. (2015) Fixed Point Theorems and Generalizations of Dislocated Metric Spaces. Indian Journal of Science and Technology, 8, 154-158. http://dx.doi.org/10.17485/ijst/2015/v8iS3/62247

[7] Panthi, D. (2015) Common Fixed Point Theorems for Compatible Mappings in Dislocated Metric Space. International Journal of Mathematical Analysis, 9, 2235-2242. http://dx.doi.org/10.12988/ijma.2015.57177

[8] Panthi, D. (2014) Fixed Point Results in Cyclic Contractions of Generalized Dislocated Metric Spaces. Annals of Pure and Applied Mathematics, 5, 192-197.

[9] Panthi, D. and Kumari, P.S. (2016) Some Integral Type Fixed Point Theorems in Dislocated Metric Space. American Journal of Computational Mathematics, 6, 88-97. http://dx.doi.org/10.4236/ajcm.2016.62010

[10] Panthi, D. and Kumari, P.S. (2015) Common Fixed Point Theorems for Mappings of Compatible Type(A) in Dislocated Metric Space. Nepal Journal of Science and Technology, 16, 79-86. http://dx.doi.org/10.3126/njst.v16i1.14360

[11] Panthi, D. and Jha, K. (2012) A Common Fixed Point of Weakly Compatible Mappings in Dislocated Metric Space. Kathmandu University Journal of Science, Engineering and Technology, 8, 25-30.

[12] Sarma, I.R., Rao, J.M., Kumari, P.S. and Panthi, D. (2014) Convergence Axioms on Dislocated Symmetric Spaces. Abstract and Applied Analysis, 2014, Article ID: 745031.

[13] Jungck, G. and Rhoades, B.E. (1998) Fixed Points for Set Valued Functions without Continuity. Indian Journal of Pure and Applied Mathematics, 29, 227-238.

[14] Amri, M. and El Moutawakil, D. (2002) Some New Common Fixed Point Theorems under Strict Contractive Conditions. Journal of Mathematical Analysis and Applications, 270, 181-188. http://dx.doi.org/10.1016/S0022-247X(02)00059-8

[15] Sintunavarat, W. and Kumam, P. (2011) Common Fixed Points for a Pair of Weakly Com- 
patible Maps in Fuzzy Metric Spaces. Journal of Applied Mathematics, 2011, 1-14. http://dx.doi.org/10.1155/2011/637958

Submit or recommend next manuscript to SCIRP and we will provide best service for you:

Accepting pre-submission inquiries through Email, Facebook, LinkedIn, Twitter, etc. A wide selection of journals (inclusive of 9 subjects, more than 200 journals)

Providing 24-hour high-quality service

User-friendly online submission system

Fair and swift peer-review system

Efficient typesetting and proofreading procedure

Display of the result of downloads and visits, as well as the number of cited articles

Maximum dissemination of your research work

Submit your manuscript at: http://papersubmission.scirp.org/

Or contactapm@scirp.org 